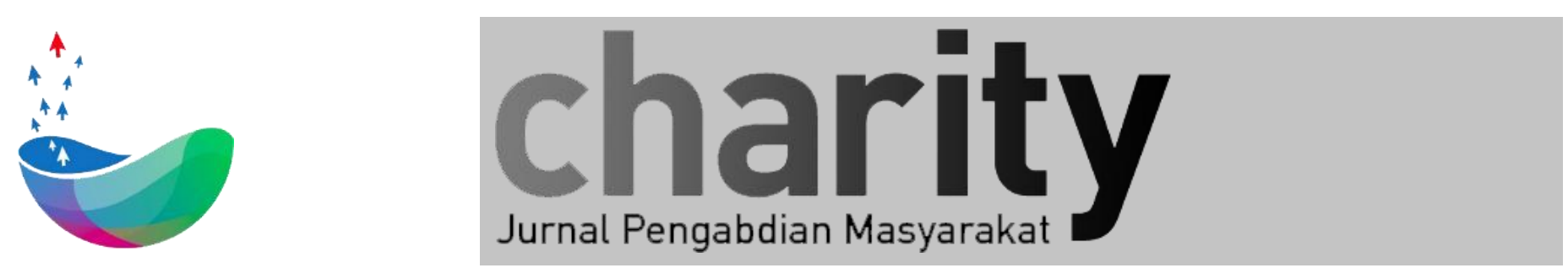

\title{
PELATIHAN MEDIA DIGITAL DAN WORKSHOP DESIGN THINKING BAGI PELAKU USAHA MIKRO KECIL DAN MENENGAH (UMKM) PADA KOPERASI MANDIRI UNGGULAN BANDUNG (SIMAUNG)
}

\author{
Rahmiati Aulia, S.Sn., M.M. ${ }^{1}$, Aria Ar Razi, S.Ds., M.Ds. ${ }^{2}$ \\ Desain Komunikasi Visual, Fakultas Kreatif Industri, Universitas Telkom \\ Desain Komunikasi Visual, Fakultas Kreatif Industri, Universitas Telkom \\ * raulia@ telkomuniversity.ac.id, ariaarrazi@ telkomuniversity.ac.id
}

\section{INFO ARTIKEL}

Diterima 22 Maret 2021

Direvisi 12 November 2021

Disetujui 07 Desember 2021

Tersedia Online 04 Februari 2022

\begin{abstract}
ABSTRAK
Situasi Pandemi Covid-19 yang terjadi secara global termasuk di Indonesia, mampu memberikan gambaran bagaimana situasi ini memiliki dampak langsung yang signifikan terhadap ketahanan para pelaku Usaha Mikro Kecil dan Menengah (UMKM). Selain menghadapi situasi pandemi dengan perubahan yang mendadak, permasalahan yang masih paling sering dijumpai adalah ketidaksiapan para pelaku UMKM di tengah perkembangan era digital. Padahal dengan mengembangkan produk/jasa yang ditawarkan serta memanfaatkan media digital yang bersifat daring, harapannya para pelaku UMKM mampu mempertahankan keberlangsungannya ditengah kondisi yang terjadi saat ini. Pengadaan workshop design thinking menjadi salah salah satu metode yang diharapkan mampu membuat UMKM mengembangkan produknya ditambah lagi dengan adanya pelatihan penggunaan digital media akan memperluas pasar mereka. Kegiatan Pengabdian kepada Masyarakat Program studi Desain Komunikasi Visual yang telah diadakan menjadi solusi para pelaku UMKM dalam mengembangkan produk/jasa yang mereka tawarkan serta memudahkan mereka memanfaatkan perkembangan serta fitur media digital dalam menghadapi persaingan pasar daring.
\end{abstract}

Keyword: media digital, digitalisasi, design thinking, Usaha Mikro Kecil dan Menengah Korespondensi:

Direktorat Penelitian dan Pengabdian Masyarakat, Universitas Telkom

Jl. Telekomunikasi No. 1, Terusan Buah Batu, Bandung, 40257

Indonesia

E-mail : ppm@telkomuniversity.ac.id

ORCID ID: 0000-0002-5648-6308

Penulis Pertama: Rahmiati Aulia, S.Sn., M.M.

https://doi.org/xxx

Paper_reg_number xxx (C) The Authors. Published by Directorate of Research and Community Service, Telkom University. 
This is an open access article under the xxx license (https://creativecommons.org/licenses/xxx)

\section{Pendahuluan}

UMKM seringkali disebut menjadi tulang punggung perekonomian dan penunjang ekonomi daerah di Indonesia. Kehadiran UMKM sendiri dianggap sebagai sektor ekonomi tahan terhadap krisis serta penggerak perekonomian yang fleksibel dan adaptable pada situasi ekonomi apapun. Namun Pandemi Covid-19 yang terjadi, mampu memberikan gambaran bagaimana situasi Pandemi memiliki dampak langsung yang signifikan terhadap ketahanan para pelaku UMKM. Sebagian pelaku UMKM dirasa belum siap dengan kondisi yang terjadi padahal bisnis yang mampu bertahan adalah bisnis yang responsif terhadap perubahan. Dan juga pada praktiknya juga masih terdapat banyak berbagai masalah yang ditemui. Dengan situasi saat ini, seharusnya para pelaku UMKM memetakan ulang permasalahan, dengan mencari alternatif dengan berinovasi dan melakukan perkembangan media digital[1][2].
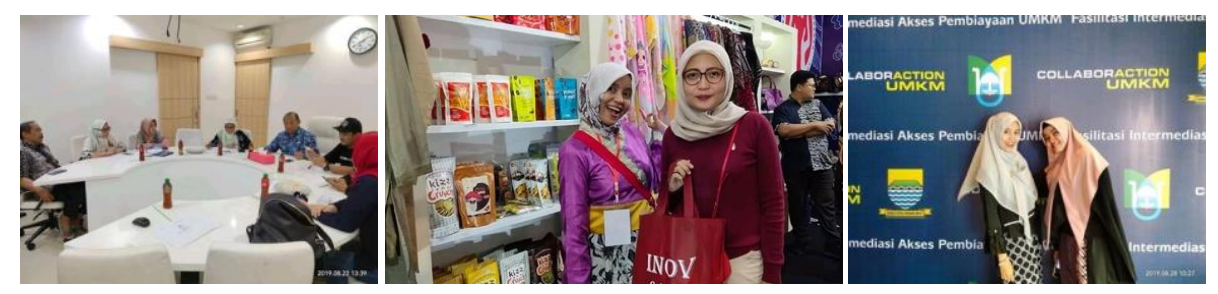

Gambar 1. Foto Kegiatan yang dilakukan Koperasi Mandiri Unggulan

Bandung (SIMAUNG)

Berdasarkan fenomena tersebut, serta mempertimbangkan betapa besarnya potensi pada Usaha Mikro Kecil dan Menengah (UMKM) yang tergabung dalam Koperasi Mandiri Unggulan Bandung (SIMAUNG) untuk keluar dari permasalahan yang telah dihadapi dan tumbuh berkembang, maka pada kesempatan ini, tim Pengabdian pada Masyarakat akan mengadakan "Pelatihan Media Digital dan Workshop Design Thinking bagi Pelaku Usaha Mikro Kecil dan Menengah (UMKM) pada Koperasi Unggulan Bandung (SIMAUNG)". Pengenalan para pelaku UMKM terhadap metode design thinking diharapkan akan dapat memetakan ulang permasalahan mendasar yang dihadapi, untuk dapat menghasilkan berbagai inovasi bagi produk UMKM yang dihasilkan itu sendiri pada masa yang akan datang. Metode ini dirasa sangat tepat untuk menangani permasalahan pelaku UMKM yang beragam, karena pada metode ini dikenal sebagai suatu metode proses berpikir komprehensif yang berkonsentrasi untuk menciptakan solusi yang diawali dengan proses empati terhadap suatu kebutuhan tertentu yang berpusat pada manusia (human centered) menuju pada inovasi berkelanjutan berdasarkan kebutuhan dari penggunanya. Sementara itu dengan diadakannya pelatihan media digital, tentunya akan sangat bermanfaat bagi para pelaku UMKM tersebut untuk meningkatkan proses penjualan yang dihasilkan agar dapat lebih efektif melalui pemanfaatan media digital[3]. 


\section{Metode Pelatihan}

Kegiatan pelaksanaan abdimas oleh Tim Dosen akan melakukan penawaran untuk mempresentasikan maksud, tujuan dan rencana kegiatan setelah melakukan wawancara terhadap key responden sebelumnya. Selanjutnya tim dosen akan mempersiapkan materi/bahan untuk diberikan kepada Pelaku UMKM. Kemudian, pada hari yang telah disepakati, tim dosen memberikan pelatihan/workshop baik itu secara daring maupun tatap muka. Setelah program pelatihan selesai maka selanjutnya akan diadakan evaluasi dan pelaporan kegiatan.

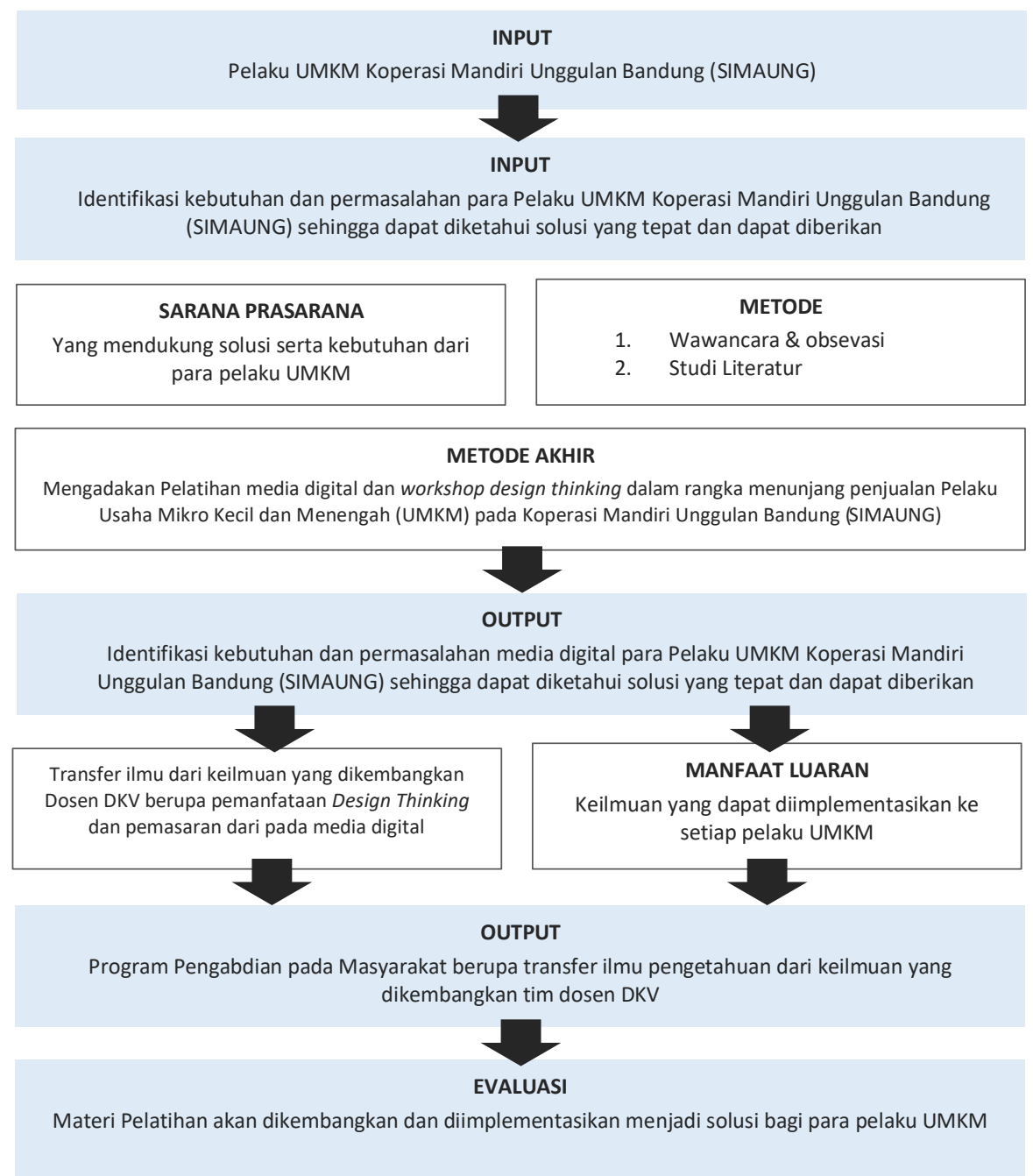

Gambar 2. Gambaran IPTEK yang Ditransfer ke Mitra.

\subsection{Wawancara dan Survei Mitra Pengabdian pada Masyarakat}

Proses pencarian data dan informasi mengenai mitra pengabdian pada masyarakat dimulai pada tahun 2020 yang lalu. Situasi Pandemi Covid-19 memberikan gambaran bagaimana situasi ini memiliki dampak langsung yang signifikan terhadap ketahanan para pelaku UMKM. Selain kondisi pandemi, pada praktiknya juga masih terdapat banyak berbagai permasalahan yang kerap menyelimuti para pelaku di bidang usaha ini. Harusnya dengan situasi saat ini, 
justru sudah seharusnya para pelaku UMKM memetakan ulang permasalahan, mencari alternatif terhadap perkembangan media digital.

Berdasarkan informasi yang diperoleh dari wawancara dengan Ibu Tita Wulansari selaku ketua dan penggiat UMKM serta pegiat Koperasi Mandiri Unggulan Kota Bandung (SIMAUNG), permasalahan yang sering dijumpai adalah kesiapan para pelaku UMKM di tengah perkembangan era digital. Saat ini terdapat sekitar 30 jenis UMKM yang tergabung dalam Koperasi Mandiri Unggulan Bandung (SIMAUNG) yang bergerak di bidang kuliner, fashion dan kriya. Tren pemasaran di dunia beralih dari yang semula konvensional (offline) menjadi digital (online). Kenyataan yang didapati membuktikan bahwa sebagian UMKM masih belum bertransformasi menjadi UMKM yang go digital yang memanfaatkan e-commerce dalam melakukan kegiatan penjualan produknya. Dari tahap ini didapat informasi awal untuk kemudian dirumuskan materi kegiatan pengabdian pada masyarakat yang akan dilakukan[2].

\subsection{Penyusunan Materi}

Materi pelatihan media digital dan workshop design thinking dalam rangka menunjang penjualan Pelaku Usaha Mikro Kecil dan Menengah (UMKM) pada Koperasi Mandiri Unggulan Bandung (SIMAUNG). Pelatihan media digital dan workshop design thinking dilakukan secara tatap muka. Kegiatan ini memiliki potensi untuk dilanjutkan dikemudian hari dengan pemberian materi yang berbeda disesuaikan dengan kebutuhan mitra[4]-[7].

Beberapa materi yang disampaikan pada pelatihan media digital dan workshop design thinking antara lain:

1. Rekap hasil penelitian awal kebutuhan UMKM.

2. Mengenalkan apa itu Design Thinking.

3. Menjelaskan perlunya Design Thinking bagi pelaku UMKM.

4. Menjelaskan peran Design Thinking dalam menciptakan inovasi?

5. Menjabarkan jenis-jenis inovasi.

6. Mengenalkan tahapan dalam Design Thinking.

7. Pemaparan Studi Kasus dalam Design Thinking.

8. Bagaimana kiat dan tips dalam pengaplikasian Design Thinking pada lingkup Usaha Mikro Kecil dan Menengah (UMKM) pada Koperasi Mandiri Unggulan Bandung (SIMAUNG)[8]. 


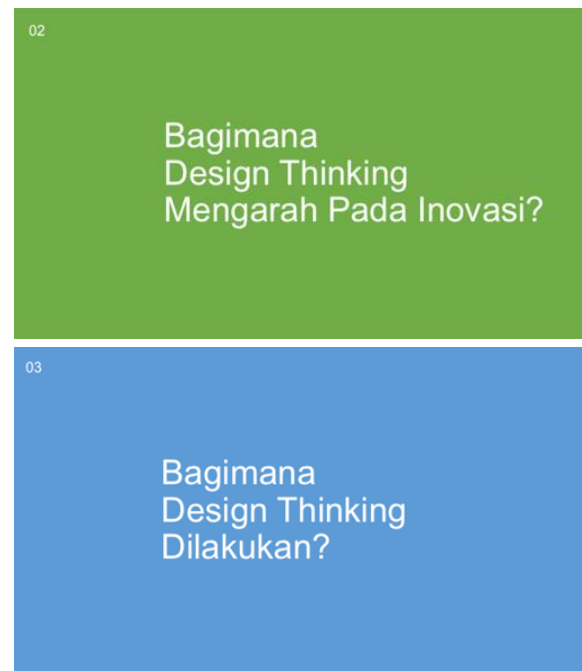

Peran Design Thinking

dalam menciptakan Inovasi
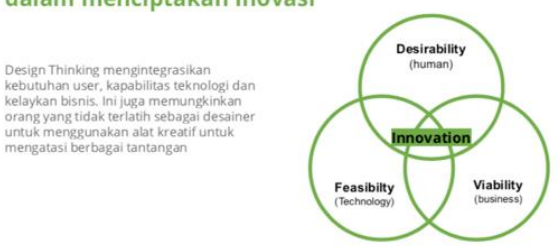

Prosess

Design Thinking

Bagimana

Design Thinking

Dilakukan?

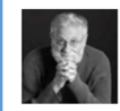

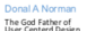

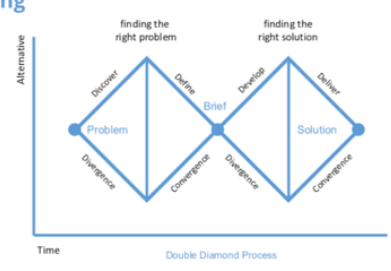

Design Thinking

Prosess

Design Thinking
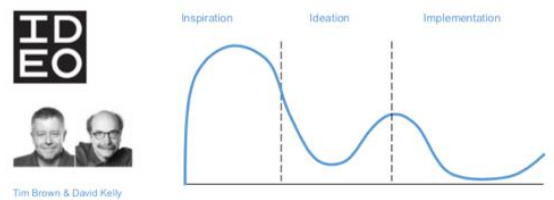

d. 1000

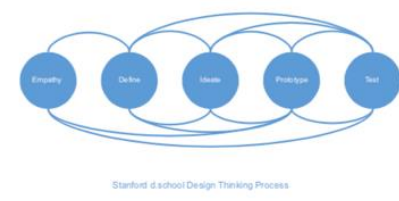

Gambar 3. Materi Workshop Design Thinking

\section{Analisa \& Hasil Kegiatan}

Pelaksanaan kegiatan pengabdian pada masyarakat berupa "Pelatihan Media Digital dan Workshop Design Thinking bagi Pelaku Usaha Mikro Kecil dan Menengah (UMKM) pada Koperasi Mandiri Unggulan Bandung (SIMAUNG)" dilakukan pada:

Hari, tanggal : Sabtu, 20 Maret 2021

Pukul : $13.00 \mathrm{WIB}$ - selesai

Lokasi : Mercure Bandung Nexa Supratman

Jl. Supratman No.66-68, Kota Bandung, 40122

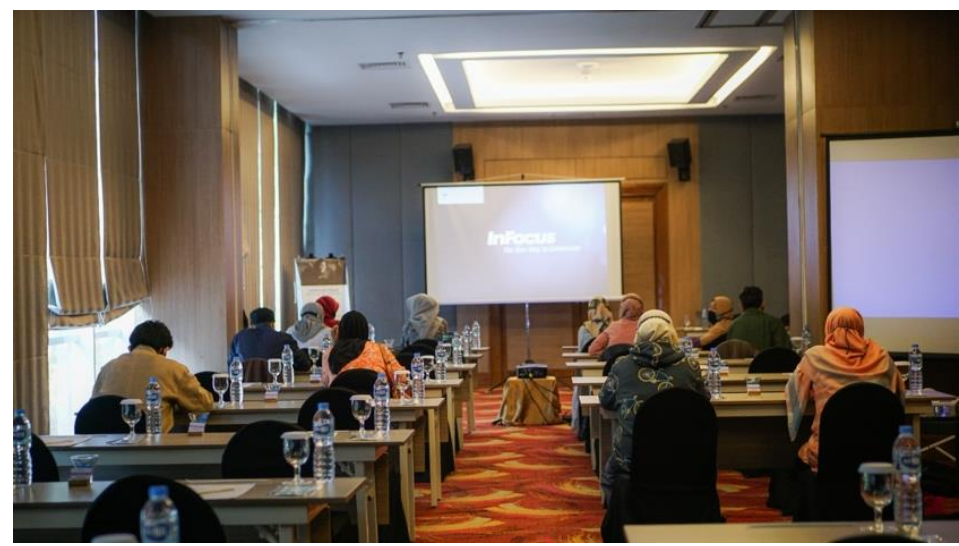

Gambar 4. Tempat Acara 
Pemberi materi menjelaskan terlebih dahulu mengenai pemahaman design thinking yang dapat diadaptasi pada Usaha Mikro Kecil dan Menengah. Kemudian dilanjutkan dengan peserta UMKM mempraktekkan tahapan proses design thinking tersebut secara langsung pada dua produk terpilih. Dengan metode ini diharapkan materi yang disampaikan dapat langsung dimengerti oleh peserta pelatihan.
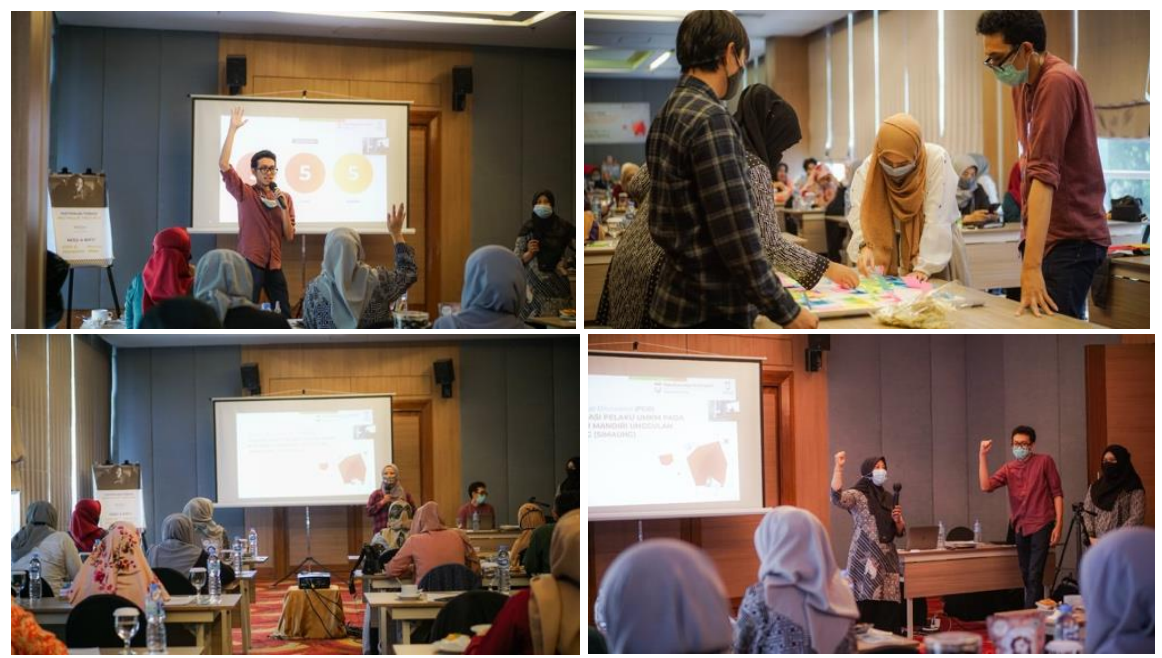

Gambar 5. Situasi Pelatihan Media Digital dan Workshop Design Thinking
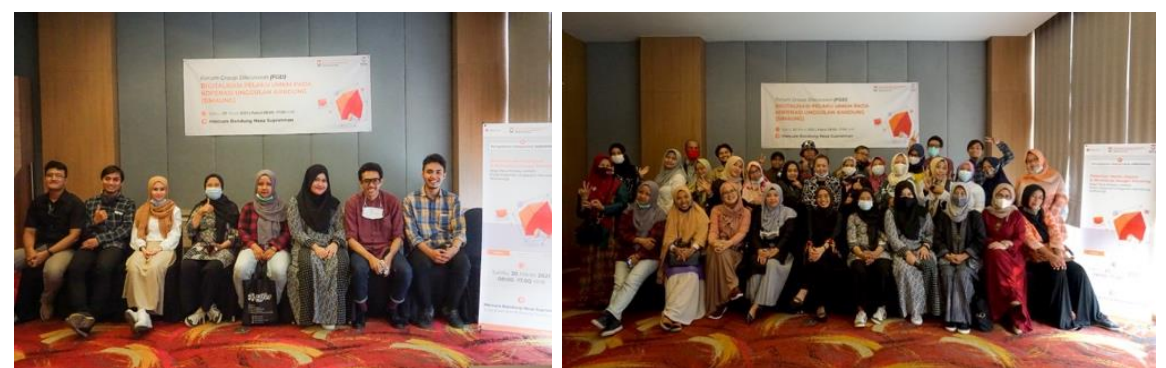

Gambar 6. Tim beserta Peserta Pelatihan Workshop

Pelatihan ini dihadiri oleh 28 orang Pelaku Usaha Mikro Kecil dan Menengah (UMKM) pada Koperasi Mandiri Unggulan Bandung (SIMAUNG). Selain partisipasi sebagai peserta pelatihan, pihak Pelaku Usaha Mikro Kecil dan Menengah (UMKM) pada Koperasi Mandiri Unggulan Bandung (SIMAUNG) juga aktif berpartisipasi dalam membantu memetakan permasalahan untuk dapat diketahui materi dan solusi apa saja terkait permasalahan yang dihadapi tersebut.

Kuesioner dibagikan pada para peserta setelah pelatihan media digital dan workshop design thinking selesai dengan mengisi google form. Terkumpul feedback dari 28 peserta pelatihan. Berikut ini adalah tabel rekap hasil feedback: 
Tabel 2. Rekap hasil feedback

\begin{tabular}{|c|c|c|c|c|}
\hline \multirow[b]{2}{*}{ Penilaian Terhadap Kegiatan } & \multicolumn{4}{|c|}{ Jumlah Faktor yang Dipentingkan } \\
\hline & $\begin{array}{l}\text { Sangat } \\
\text { tdk } \\
\text { setuju }\end{array}$ & $\begin{array}{l}\text { Tidak } \\
\text { setuju }\end{array}$ & Setuju & $\begin{array}{l}\text { Sangat } \\
\text { setuju }\end{array}$ \\
\hline $\begin{array}{l}\text { 1. Kejelasan pemateri dan penyampaian } \\
\text { materi. }\end{array}$ & & & 13 & 15 \\
\hline $\begin{array}{l}\text { 2. Kegiatan ini sudah sesuai dengan } \\
\text { kebutuhan masyarakat sasar. }\end{array}$ & & & 11 & 17 \\
\hline 3. Keterkaitan materi yang disampaikan. & & & 10 & 18 \\
\hline $\begin{array}{l}\text { 4. Dosen dan mahasiswa Universitas Telkom } \\
\text { bersikap ramah, cepat dan tanggap } \\
\text { membantu selama kegiatan. }\end{array}$ & & & 11 & 17 \\
\hline $\begin{array}{l}\text { 5. Masyarakat setempat menerima dan } \\
\text { mengharapkan kegiatan Universitas } \\
\text { Telkom saat ini dan masa yang akan } \\
\text { datang. }\end{array}$ & & & 12 & 16 \\
\hline Jumlah & 0 & 0 & 57 & 83 \\
\hline \% (Jumlah masing-masing : total) & 0 & 0 & $41 \%$ & $59 \%$ \\
\hline Jumlah \% setuju+sangat & \multicolumn{4}{|c|}{$100 \%$} \\
\hline
\end{tabular}

Berdasarkan tabel feedback diatas, dapat disimpulkan bahwa program pengabdian pada masyarakat yang telah diselenggarakan dinilai sangat baik, yaitu jumlah setuju dan sangat setuju mencapai lebih dari $80 \%$, sebesar $100 \%[9]$.

\section{Kesimpulan dan Saran}

Evaluasi pelaksanaan program adalah membagikan keilmuan kepada Pelaku Usaha Mikro Kecil dan Menengah (UMKM) pada Koperasi Mandiri Unggulan Bandung (SIMAUNG). Dalam hal ini dipilih para Pelaku Usaha Mikro Kecil dan Menengah (UMKM) dengan harapan, melalui kegiatan pelatihan ini dapat membantu pengembangan serta memetakan ulang permasalahan mendasar yang tengah dihadapi, untuk kemudian dapat menghasilkan berbagai inovasi yang dihasilkan agar dapat meningkatkan kemampuan saing dalam media digital.

Masukan dan feedback peserta terhadap pelatihan yang sudah dilakukan dapat dilihat dari hasil kuesioner. Dari kuesioner tersebut, 100\% peserta merespon bahwa pelatihan/workshop yang diadakan sesuai dengan tujuan kegiatan tersebut, serta sesuai dengan kepentingan dan kebutuhan mitra masyarakat sasar. Responden juga memberi tanggapan positif terhadap presentasi yang dilakukan oleh dosen dan mahasiswa Telkom University selaku penyelenggara. Kebanyakan responden mengharapkan adanya pelatihan lanjutan dan mendalam. Keberlanjutan setelah kegiatan program dilaksanakan, diharapkan materi yang diberikan dapat diimplementasikan pada produk dan media digital. 


\section{DAFTAR PUSTAKA}

[1] OECD, "Coronavirus (COVID-19): SME Policy Responses," 2020. .

[2] S. Purwana ES, Dedi, Rahmi, Aditya, "Pemanfaatan Digital Marketing Bagi Usaha Mikro, Kecil , Dan Menengah ( Umkm )," J. Pemberdaya. Masy. Madani, 2017, doi: doi.org/10.21009/JPMM.001.1.01.

[3] A. K. Pakpahan, "Covid-19 Dan Implikasi Bagi Usaha Mikro, Kecil, Dan Menengah," J. IIm. Hub. Int., vol. 0, no. 0, pp. 59-64, 2020, doi: 10.26593/jihi.v0i0.3870.59-64.

[4] A. A. Razi, I. R. Mutiaz, and P. Setiawan, "PENERAPAN METODE DESIGN THINKING PADA MODEL PERANCANGAN UI/UX APLIKASI PENANGANAN LAPORAN KEHILANGAN DAN TEMUAN BARANG TERCECER," Desain Komun. Vis. Manaj. Desain dan Periklanan, 2018, doi: 10.25124/demandia.v3i02.1549.

[5] J. W. Creswell and J. D. Cresswell, Research and design qualitative, quantitative and mixed methods approaches. 2018.

[6] M. Jazuli, "Metode Penelitian Kualitatif," Semarang Jur. Sendratasik Univ. Negeri Semarang, 2001.

[7] T. Brown and B. Katz, "Change by design," J. Prod. Innov. Manag., 2011, doi: 10.1111/j.1540-5885.2011.00806.x.

[8] H. Plattner, "An introduction to design thinking," linstitute Des. Stanford, pp. 1-15, 2013.

[9] R. Aulia, A. Syafikarani, and O. A. Supriadi, "Menunjang Pembelajaran Daring, Guru Smp Bina Taruna," vol. 04, no. 01, pp. 53-60, 2021. 